\title{
Pumping Capacity of Pitched Blade Impellers in a Tall Vessel with a Draught Tube
}

\author{
J. Brož, I. Fořt, R. Sperling, S. Jambere, M. Heiser, F. Rieger
}

A study was made of the pumping capacity of pitched blade impellers (two, three, four, five and six blade pitched blade impellers with pitch angles $\alpha=35^{\circ}$ and $45^{\circ}$ ) coaxially located in a cylindrical pilot plant vessel with cylindrical draught tube provided with a standard dished bottom. The draught tube was equipped with four equally spaced radial baffles above the impeller pumping liquid upwards towards the liquid surface. In all investigated cases the liquid aspect ratio $H / T=1.2-1.5$, the draught tube / vessel diameter ratios $D_{T} / T=0.2$ and 0.4 and the impeller / draught tube diameter ratio $D / D_{T}=0.875$. The pumping capacity of the impeller was calculated from the radial profile of the axial component of the mean velocity in the draught tube below the impeller at such an axial distance from the impeller that the rotor does not affect the vorticity of the flow. The mean velocity was measured using a laser Doppler anemometer with forward scatter mode in a transparent draught tube and a transparent vessel of diameter $T=400 \mathrm{~mm}$.

Two series of experiments were performed, both of them under a turbulent regime of flow of the agitated liquid. First, the optimum height of the dished bottom was sought, and then the dependences of the dimensionless flow rate criterion and the impeller power number on the number of impeller blades were determined for both pitch angles tested under conditions of optimum ratio $H_{T} / D_{T}$. It follows from the results of the experiments that the optimum ratio $H_{T} / D_{T}=0.25$ when the cross sectional areas of the horizontal flow around the bottom and the vertical inflow to the draught tube are the same. For all the tested pitched blade impellers the impeller power number when $\alpha=45^{\circ}$ exceeds the value of this quantity when pitch angle $\alpha=35^{\circ}$, while the flow rate number when $\alpha=35^{\circ}$ exceeds this quantity when $\alpha=45^{\circ}$. On the other hand, the absolute values of the impeller power number when the draught tube was introduced correspond fairly well to the dimensionless impeller power input measured in a system without a draught tube. However, the absolute values of the flow rate number found in the former system are significantly lower than the dimensionless impeller pumping capacity determined in the latter system. The hydraulic efficiency of pitched blade impellers $N_{Q_{p}}^{3} / P$ o for the investigated geometry of the agitated systems does not depend on the number of impeller blades, but it is significantly lower than the quantity determined in an agitated system with a dished bottom but without the draught tube.

Keywords: pitched blade impeller, impeller pumping capacity, draught tube, laser Doppler anemometer, turbulent flow.

\section{Introduction}

The pumping capacity of a pitched blade impeller (PBT) in a draught tube is defined as the amount of liquid leaving the outlet base of the draught tube per unit time. This quantity is an important process characteristic of the PBT and plays an important role when calculating the process characteristics of solid-liquid suspensions in a system with a draught tube $[1,2,3]$ or without this internal [4], i.e. above the impeller frequency for just off bottom suspension.

The pumping capacity of a PBT can be measured by the indirect "flow follower" (indicating particle) method [5] and calculated from the measured mean time of liquid primary circulation, or calculated from the radial profile of the axial component of the mean velocity in the impeller discharge stream $[4,6]$ or in the draught tube $[1,2]$ by means of integration over the cross section of the impeller rotor region or over the cross section of the draught tube.

The pumping capacity of the PBT, $Q_{p}$, can be expressed in dimensionless form as the impeller flow rate number [5, 8]

$$
N_{Q_{p}}=Q_{p} / n D^{3}
$$

where $n$ is the frequency of the impeller revolution and $D$ is its diameter. Quantity does not depend on the impeller Reynolds number when this quantity exceeds five thousand $[7,8,9]$. For impeller power input $P$ the power number has been introduced

$$
P_{0}=P / \rho n^{3} D^{5},
$$

where $\rho$ is the density of the agitated liquid. This quantity is also independent of the impeller Reynolds number when it exceeds ten thousand. A combination of the dimensionless quantities and $P o$ gives the so called hydraulic efficiency of the impeller, defined either as [6]

$$
E=\frac{N_{Q_{p}}^{3}}{P_{0}},
$$

or as [8]

$$
E_{p}=\frac{N_{Q_{p}}^{3}}{P_{0}}\left(\frac{D}{T}\right)^{4} .
$$

The former definition is suitable for agitated systems with a draught tube [1], and the latter for systems without this internal. Quantity $T$ in Eqs. (3) and (4) denotes the diameter of the vessel. The higher the quantity $E$ or $E_{p}$, the greater the ability to convert the impeller energy consumption into its pumping effect, i.e., it is possible to study the influence of various geometries of the mixing system on the quantity $E$ or $E_{p}$. [8].

This study analyses the pumping and energetic efficiency of various pitched blade impellers in tall vessel with a draught tube, a suitable geometry for industrial applications where high homogeneity of solid-liquid suspension and temperature distribution are desirable. The PBT pumping capacity will be calculated from the radial profile of the axial compo- 
nent of the mean velocity in the draught tube. The velocity will be determined by the laser Doppler anemometer and the impeller power input by means of a strain gauge torquemeter.

\section{Experimental}

The experiments were carried out in a pilot plant cylindrical vessel (diameter $T=400 \mathrm{~mm}$ ) with a dished bottom [10]. Two series of experiments were made:

I. Optimisation of the slot $H_{T}$ between the lower edge of the draught tube and the dished bottom (see Fig. 1). Here, a six blade impeller with pitch angle $\alpha=45^{\circ}$ (see Fig. 2) pumping liquid upwards towards the liquid surface was used. The vertical (axial) distances of the lower edge of the draught tube above the bottom were set up within the interval $H_{T} \varepsilon\langle 2 \mathrm{~mm} ; 40 \mathrm{~mm}\rangle$.

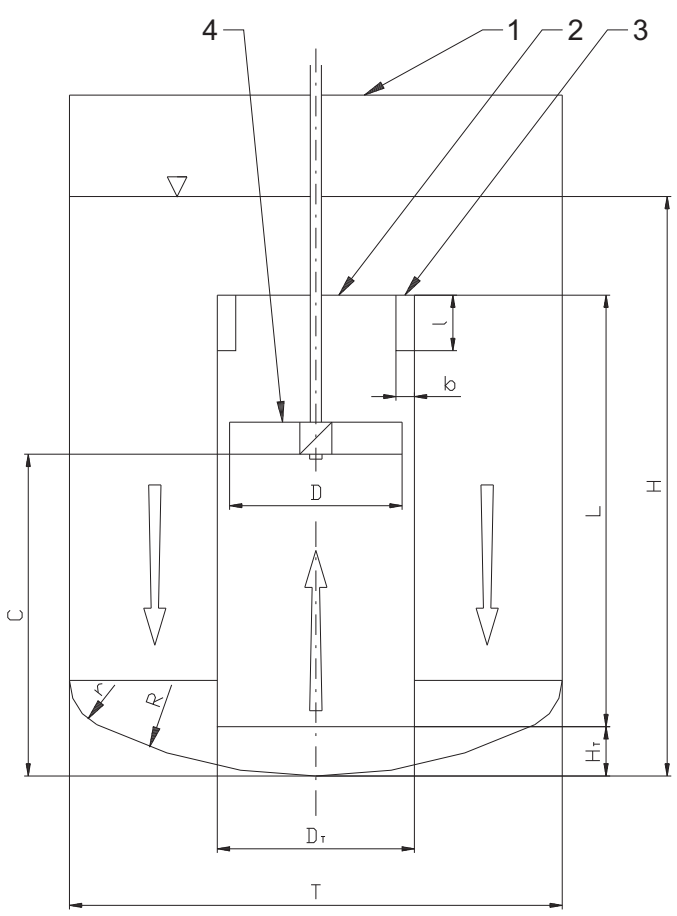

Fig. 1: Geometry of the pilot plant tall vessel with a draught tube (the $1^{\text {st }}$ series of experiments); 1 - vessel, 2 - draught tube, 3 - baffle, 4 - impeller $(H=600 \mathrm{~mm}, T=400 \mathrm{~mm}$, $L=540 \mathrm{~mm}, C=465 \mathrm{~mm}, D_{T}=80 \mathrm{~mm}, D=70 \mathrm{~mm}$, $l=70 \mathrm{~mm}, b=7 \mathrm{~mm}, R=400 \mathrm{~mm}, r=40 \mathrm{~mm}$ )
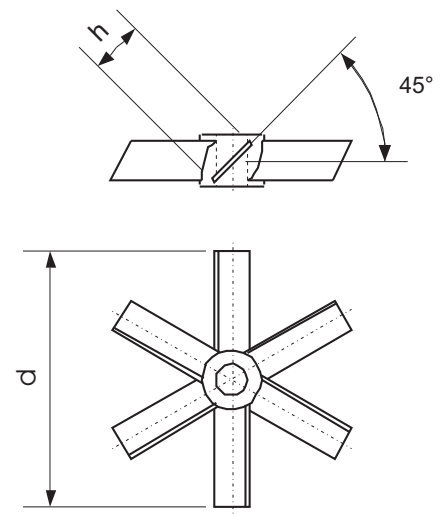

Fig. 2: Sketch of pitched blade impellers with three or six blades Czech Standard CVS 691020: a) $n_{B}=3: \alpha=35^{\circ}, 45^{\circ}$, b ) $\left.n_{B}=6, \alpha=35^{\circ}, 45^{\circ} ; h / D=0.2\right)$
II. Determination of the dependence of the impeller pumping capacity and the impeller power input on the number of impeller blades $n_{B}=2,3,4,5,6$ at two levels of pitch angle $\alpha=35^{\circ}, 45^{\circ}$ for optimum height $H_{T}$ of the lower edge of the draught tube above the bottom. All the PBTs rotated in such a way that they pumped the liquid upwards towards the surface of the liquid.

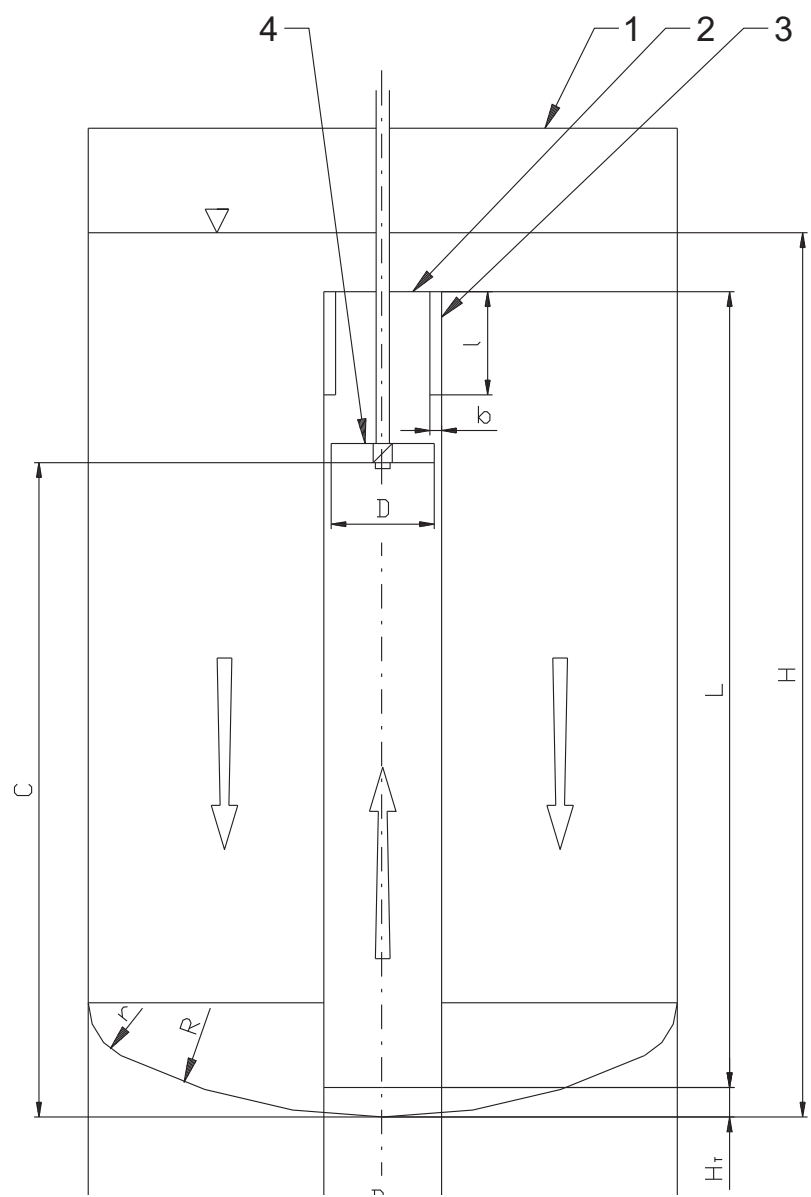

Fig. 3: Geometry of the pilot plant tall vessel with a draught tube (the $2^{\text {nd }}$ series of experiments); 1 - vessel, 2 - draught tube, 3 - baffle, 4 - impeller $(H=470 \mathrm{~mm}, T=400 \mathrm{~mm}$, $L=350 \mathrm{~mm}, C=400 \mathrm{~mm}, D_{T}=160 \mathrm{~mm}, D=140 \mathrm{~mm}$, $l=45 \mathrm{~mm}, b=15 \mathrm{~mm}, R=400 \mathrm{~mm}, r=40 \mathrm{~mm}$ )

Each draught tube was equipped with four equally spaced radial baffles equal in width of the tube to one tenth of the diameter of the tube mounted at its wall above the impeller. Water at a temperature of $20^{\circ} \mathrm{C}$ was chosen as the working liquid. The frequency of revolution of impeller $n$ was measured by means of a photoelectric cell with accuracy $\pm 1 \mathrm{rev} / \mathrm{min}$. The slot $H_{T}$ between the lower edge of the draught tube and the bottom was measured from the corresponding point vertically above the bottom, using a ruler with a precision of $\pm 1 \mathrm{~mm}$. The error in measuring the blade angle of the PBTs can be considered as $\pm 0.5^{\circ}$.

The mean velocity field in the draught tube was measured in the inlet area below the impeller in various cross sections. For the $1^{\text {st }}$ series of experiments the following vertical axial coordinates of the cross sections were chosen: 1, 15, 45, 90 and $130 \mathrm{~mm}$ below the lower edges at the impeller and for the $2^{\text {nd }}$ series the following axial coordinates: 30, 60, 90 and 120 $\mathrm{mm}$ below the lower edges of the impeller. 


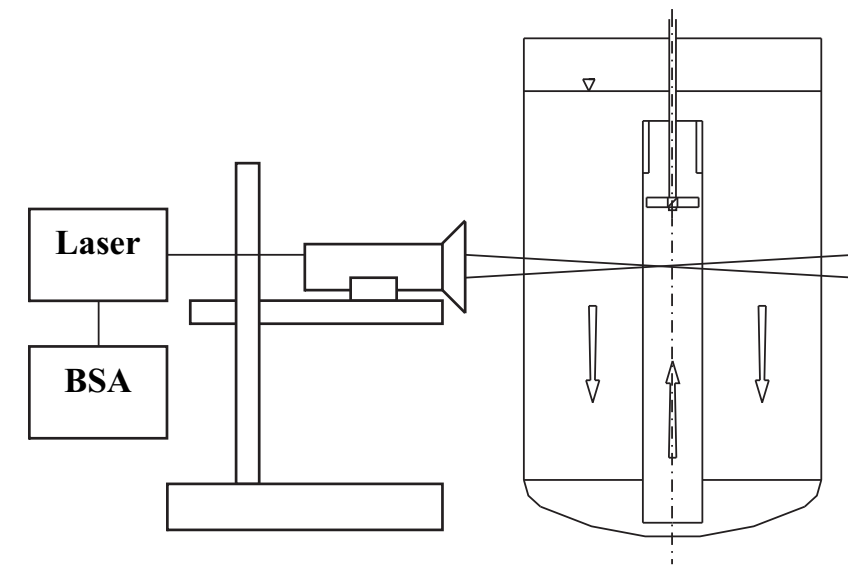

Fig. 4: Layout of a laser Doppler anemometer with forward scatter mode

The mean velocity was determined from the measurements made by means of a laser Doppler anemometer (LDA). A DANTEC 55X two component modular series LDA and its associated BSA data processor, connected with a PC, was used for the experiments. The LDA was operated in a forward scatter mode (see Fig. 4). The laser (5 W Ar ion, manufactured by Spectra Physics, USA) and optics were mounted on a bench with a two-dimensional traversing mechanism. To identify the flow reversals correctly, a frequency shift was given to one of the beams by means of a Bragg cell with electronic downmixing. Two components of the local velocity were measured simultaneously, with positioning accuracy $\pm 0.1 \mathrm{~mm}$. The sam-
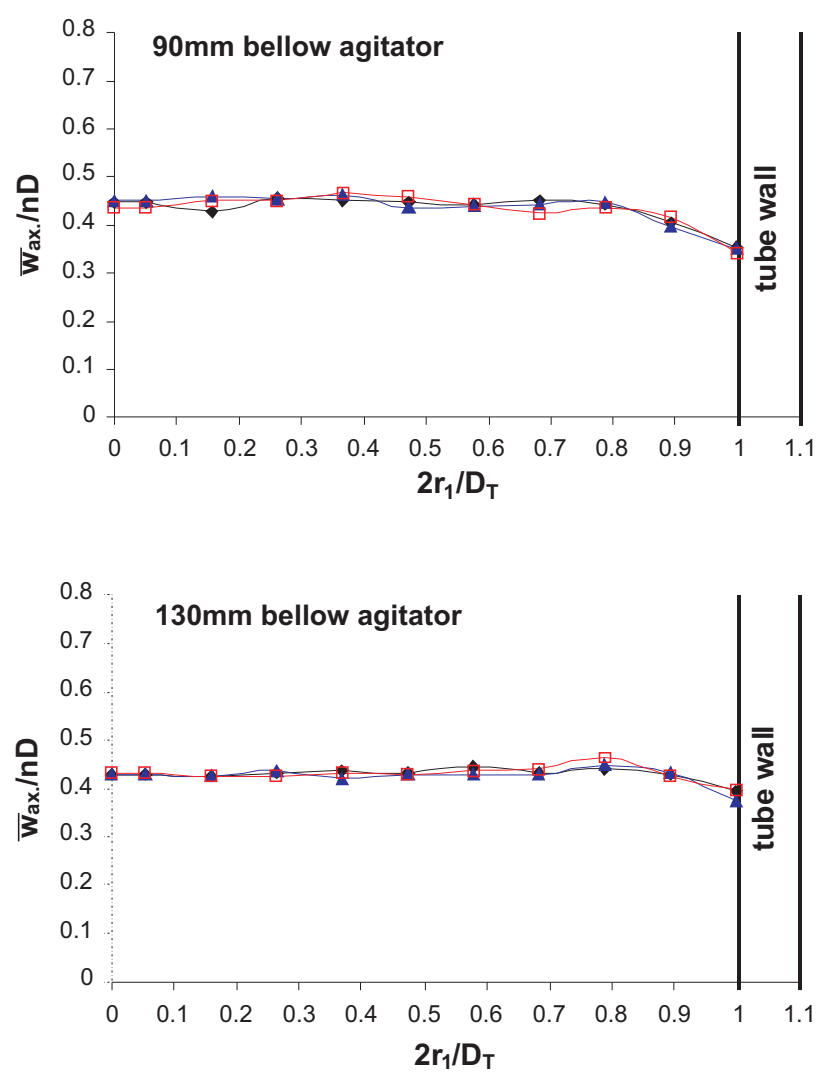

Fig. 5: Radial distribution of the axial component of the mean velocity in the inlet zone of the tube below PBT (size blade PBT $-\alpha=45^{\circ}$ ), $n=500 \mathrm{~min}^{-1}, n=600 \mathrm{~min}^{-1}$, $n=700 \mathrm{~min}^{-1}$ ple size was set at 20,000 items for each velocity measurement, and the mean time (averaged) value from all the samples was calculated. The impeller power input was also determined experimentally (with relative accuracy $\pm 10 \%$ ) by means of a strain gauge torquemeter mounted on the impeller shaft.

The impeller pumping capacity $Q_{\mathrm{p}}$ was calculated from the experimentally determined radial profiles of the mean velocity over the cross sectional area of the draught tube below the impeller (in the inlet zone) $\overline{w_{a x}}=\overline{w_{a x}}(r)$. The local value of the mean velocity corresponds to the average value of the ensemble over the circle of radius $r$ determined by LDA, assuming axial symmetry of the flow in the draught tube, and the impeller pumping capacity can be calculated from the equation

$$
Q_{p}=2 \pi \int_{0}^{D_{T} / 2} \overline{w_{a x}}(r) r \mathrm{~d} r .
$$

Fig. 5 depicts the measured radial profiles of the axial component of the mean velocity in the inlet zone of the draught tube in the $1^{\text {st }}$ series of experiments. It follows from the experiments that vorticity appears in the vicinity of the impeller owing to the rotation of impeller blades, i.e. the velocity field is significantly distorted. Therefore for calculation of the impeller pumping capacity the third and the fourth cross sectional areas below the lower edges of the impeller blades (vertical (axial) distances $130 \mathrm{~mm}$ and $90 \mathrm{~mm}$ ) were chosen. All the experiments were carried out at three levels of impeller revolution frequency under turbulent regime of flow of the agitated liquid.

The main part of the first series of experiments consisted of optimisation of the slot $H_{T}$ between the lower edge of the draught tube and the dished bottom (see Fig. 6). At a constant value of the diameter of the draught tube $D_{T}$ the vertical (axial) distance $H_{T}$ was changed. It is clear from the figure that the value of the flow rate number is practically constant when the relative height of the slot $H_{T} / D>0.25$. The lowest value of this inequality corresponds to the conditions when the cross sectional area of the vertical upflow in the inlet of the draught tube is the same as the cross sectional area of the horizontal flow in the slot

$$
\frac{\pi}{4} D_{T}^{2}=\pi D_{T} H_{T}
$$

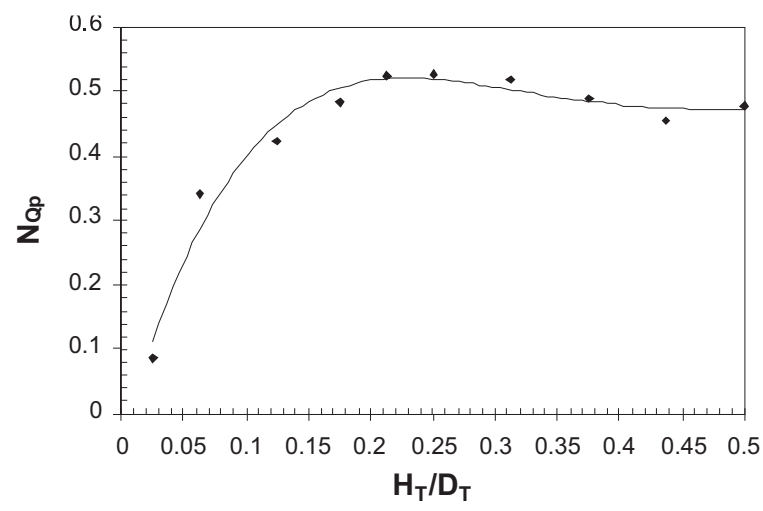

Fig. 6: Dependence of the flow rate number on ratio $\mathrm{H}_{\mathrm{T}} / \mathrm{D}_{\mathrm{T}}$ (first series of experiments), points - experimental values 


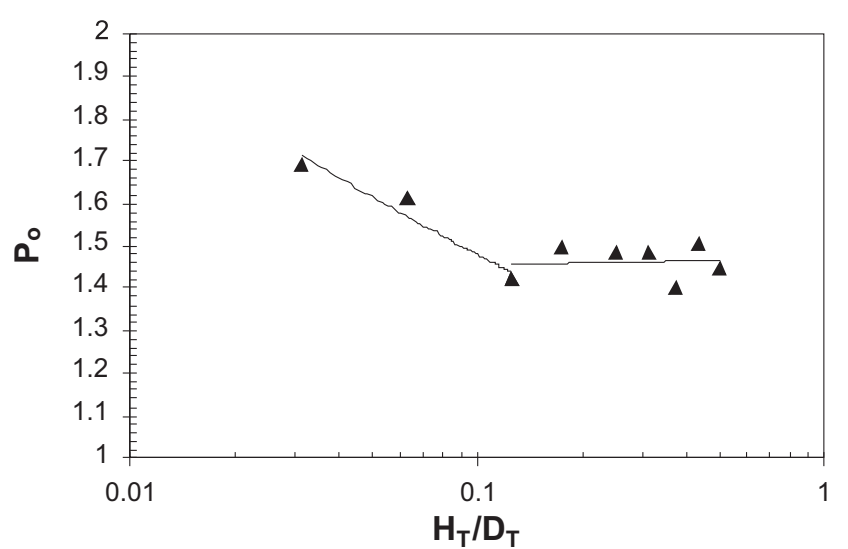

Fig. 7: Dependence of the power number on ratio $\mathrm{H}_{\mathrm{T}} / \mathrm{D}_{\mathrm{T}}$ (first series of experiments), points - experimental values

so that

$$
H_{T}=0.25 D_{T} .
$$

Similarly, the power number is independent of the ratio $H_{T} / D_{T}$ when its holds

$$
H_{T} / D_{T}>0.1 \text {, }
$$

as shown in Fig. 7. Moreover, it is expected that the power number is independent of the impeller Reynolds number under turbulent regime of flow of the agitated liquid.

Above the limit expressed by Eq. (7) the average axial component of the mean velocity over the slot depends on the height of the slot

$$
\overline{w_{B}}=\frac{Q_{p}}{\pi D_{T} H_{T}}=\frac{\text { const. }}{H_{T}}, \quad H_{T} / D_{T} \geq 0.25 .
$$

Fig. 8 illustrates in dimensionless form relation (8), i.e. the hyperbolic relation between dimensionless velocity and the dimensionless ratio $H_{T} / D_{T}$. It is noting that for the given geometry of the investigated system the theoretical hyperbolic dependence can be expressed in terms of Fig. 8 in the form

$$
\frac{\overline{w_{B}}}{n d}=0.119 \frac{H_{T}}{D_{T}},
$$

which fits fairly well to the experimental curve when $H_{T} / D_{T} \geq 0.125$, when the flow resistance owing to the sudden change of the cross sectional area can be neglected.

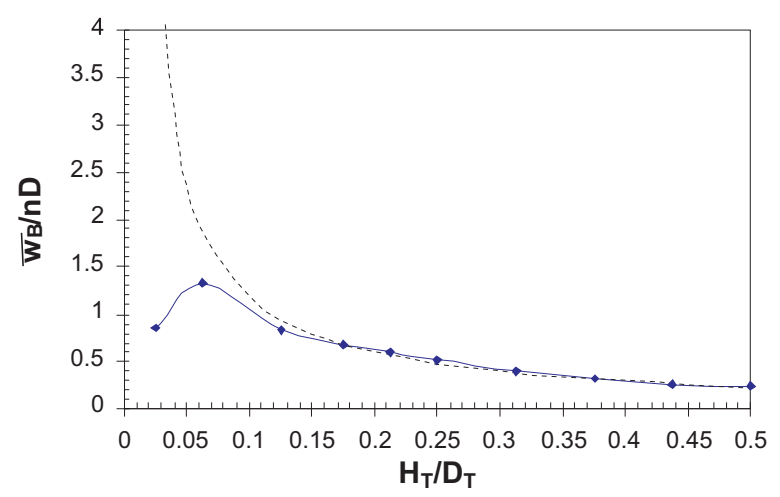

Fig. 8: Dependence of the dimensionless average axial component of the mean velocity over the slot between the lower edge of the draught tube and the dished bottom on ratio $H_{T} / D_{T}$ (first series of experiments), theoretical curve ......, points - experimental values
The results of the second series of experiments, carried out at the optimum arrangement in the vicinity of the dished bottom determined above (Eq. 7), cover the dependence of the flow rate number and the power number on the number of blades of PBT at two levels of its pitch angle. The geometry of the investigated system (see Fig. 2), although with different ratio $D_{T} / T$, corresponds to the geometric similarity of the main characteristics

$$
D / D_{T}=0.875, \quad H_{T} / D_{T}=0.25,
$$

considered for the system tested in the first series of experiments (see Fig. 1). Each geometry was investigated at five levels of frequency of revolution of the impeller and the shown values of $N_{Q_{p}}$ and $P o$ are the average data from all individual experiments results, calculated with an average error $\pm 10 \%$. All the results correspond to the fully turbulent regime of flow of an agitated liquid when the impeller Reynolds number exceeds ten thousand [5, 11].

Figs. 9 and 10 illustrate the dependence of the PBT flow rate number $N_{Q_{p}}$ and the $\mathrm{PBT}$ power number $P_{0}$, respectively, on PBT number of blades $n_{B}$. While the results of the power consumption of the impeller correspond fairly well with the results of experiments made in a standard mixing system (down pumping PBT in a vessel with four baffles at the wall and impeller off bottom clearance $C / D=0.5$ ) [11], the pumping capacity of PBT in the investigated system is significantly lower than the equivalent quantity in the above described standard system and, moreover, the quantity $Q_{P}$ for the pitch

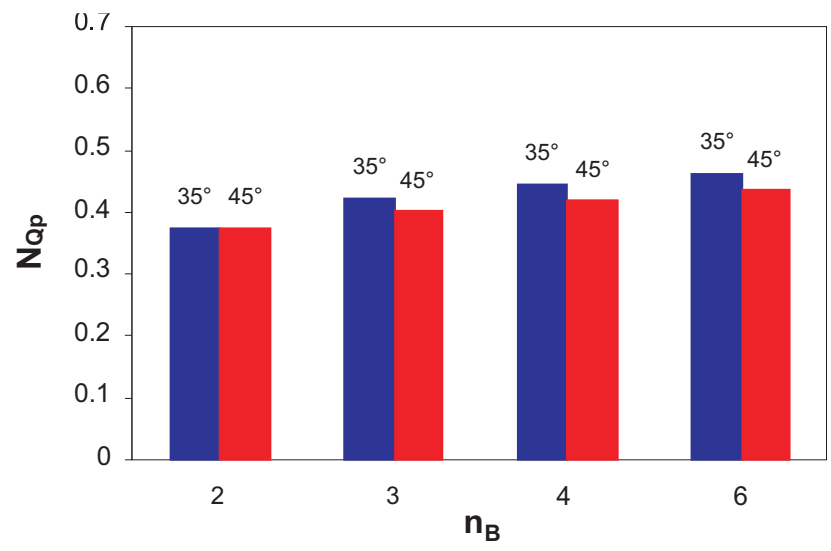

Fig. 9: Dependence of the PBT flow rate number on the number of blades of the impeller and the blade pitch angle

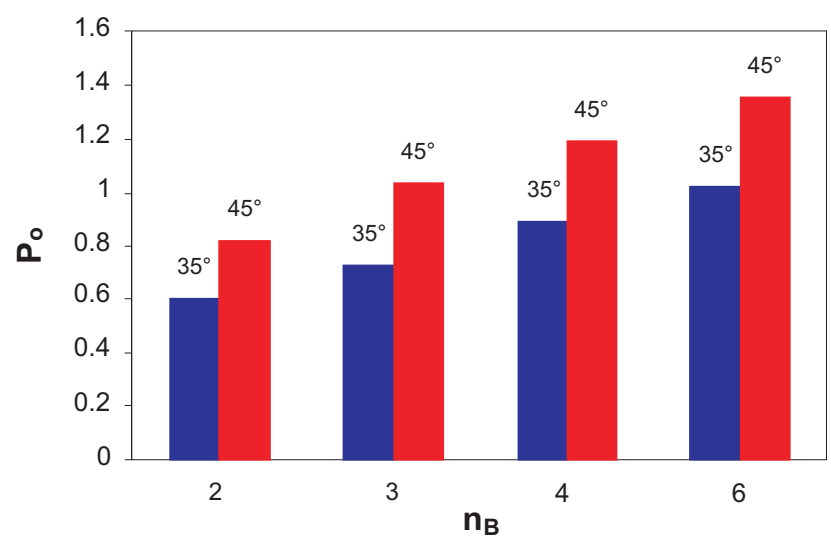

Fig.10: Dependence of the PBT power number on the number of blades the impeller and the blade pitch angle 


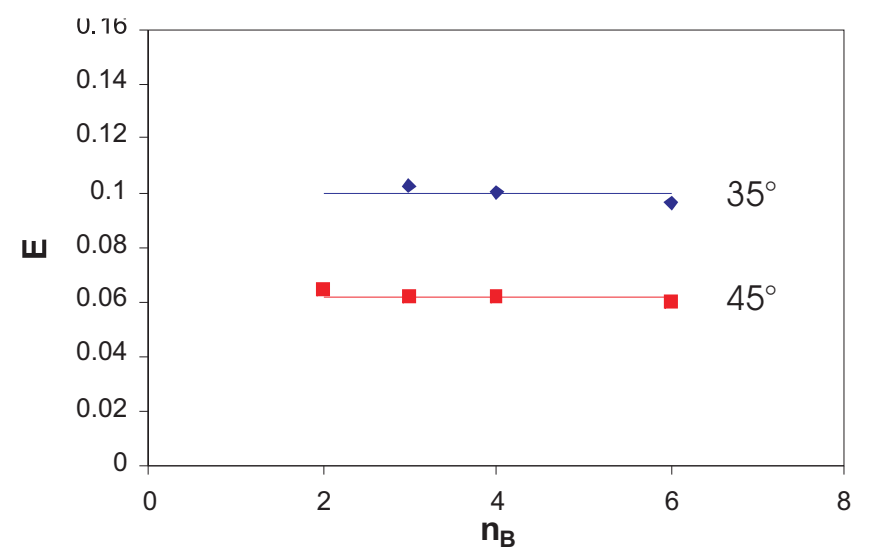

Fig. 11: Dependence of the PBT hydraulic efficiency on the number of impeller blades and the blade pitch angle, $\alpha=35^{\circ}$, $\alpha=45^{\circ}$

angle $\alpha=35^{\circ}$, except for the number of impeller blades $n_{B}=2$, exceeds this quantity when $\alpha=45^{\circ}$. On the other hand, taking to account the hydraulic efficiency of PBT (see Eq. 3) this quantity is practically independent of the number of impeller blades (see Fig. 11). This independence is in accordance with the results of the experiments made in the above described standard mixing system, but their absolute values are significantly lower than those calculated for the standard system. This difference can be explained by the longer average liquid circulation loops in the system with a draught tube than in the system with baffles only, i.e. a higher portion of the mechanical energy necessary for circulation is consumed in the former system. However, this disadvantage is significantly balanced by the suitability of the investigated system with a draught tube for suspensions of solid particles in a liquid [3]. Here the height of the sediment of solid particles can exceed the height of the vertical slot between the lower edge of the draught tube and the dished bottom. However, under relatively low frequency of revolution of the off bottom suspension effect successfully occurs. So, even after accidence of the industrial mixing unit with the solid phase, e.g. a crystallizer, it is possible to resuspend the sedimented solid particles in a system.

\section{Conclusions}

The flow rate of the agitated liquid in a cylindrical draught tube with up flow PBT does not depend on the height of the slot between the draught tube and the dished bottom, when the cross sectional area in the slot is the same or greater than the cross sectional area of the draught tube.

Both PBT flow rate number and the power number increase with increasing number of impeller blades for the tested impeller pitch angles $\alpha=35^{\circ}$ and $45^{\circ}$.

The hydraulic efficiency of both tested PBTs $\left(\alpha=35^{\circ}\right.$ and $45^{\circ}$ ) does not depend on the number of impeller blades, but, on the contrary, in an agitated system without a draught tube (with baffles at the wall only) the value of quantity $E$ when $\alpha=35^{\circ}$ exceeds the hydraulic efficiency of PBT with pitch angle $\alpha=45^{\circ}$.

\section{List of Symbols}

baffle width, [m]
$C \quad$ off bottom impeller clearance, [m]

$D$ impeller diameter, $[\mathrm{m}]$

$D_{T} \quad$ draught tube diameter, [m]

$E \quad$ impeller hydraulic efficiency (Eq. 3)

$E_{P} \quad$ impeller hydraulic efficiency (Eq. 4)

$H$ height of liquid from bottom of vessel, [m]

$H_{T}$ height of the slot between the lower edge of the draught tube and the dished bottom, [m]

$h \quad$ width of impeller blade, [m]

$L \quad$ draught tube length, [m]

$l \quad$ baffle length, [m]

$N_{Q_{p}} \quad$ impeller flow rate number

$n \quad$ frequency of impeller revolution, $\left[\mathrm{s}^{-1}\right.$ ]

$n_{B} \quad$ number of impeller blades

$P \quad$ impeller power input, $[\mathrm{W}]$

$P o \quad$ impeller power number

$Q_{p} \quad$ impeller pumping capacity, $\left[\mathrm{m}^{3} \mathrm{~s}^{-1}\right]$

$R$ radius of dished bottom, [m]

$r \quad$ radius of round corners of dished bottom, [m]

$r_{1}$ radius, [m]

$T \quad$ vessel diameter, $[\mathrm{m}]$

$\overline{w_{a x}} \quad$ axial component of the liquid mean velocity, $\left[\mathrm{m} \cdot \mathrm{s}^{-1}\right]$

$\overline{w_{B}} \quad$ mean velocity over the slot between the lower edge of the draught tube and the dished bottom, $\left[\mathrm{m} \cdot \mathrm{s}^{-1}\right]$

$\alpha \quad$ pitch angle of blade, $\left[{ }^{\circ}\right]$

$\rho \quad$ density of agitated liquid, $\left[\mathrm{kg} \cdot \mathrm{m}^{-3}\right]$

\section{Acknowledgment}

This research was supported by research project of the Ministry of Education of the Czech Republic J04/98:212200008.

\section{References}

[1] Hoštálek J., Fořt I.: "Description of vortex turbulent flow of mixed liquid.” Collect. Czech.Chem. Commun., Vol. 50 (1985), p. 930-945.

[2] Sýsová M., Fořt I., Kudrna V.: “Analytical description of the solid phase particle distribution in a mechanically agitated system." Collect. Czech. Chem. Commun. Vol. 53 (1988), p. 1198-1215.

[3] Brož J., Rieger F.: "Mixing of suspensions in tall vessels with a draught tube." Proceedings on CD ROM of the $30^{\text {th }}$ Conference of the Slovak Society of Chemical Engineers, Tatranské Matliare (Slovakia), May 2003, p. 1-8.

[4] Wu J., Zhu Y., Pullum L.: "The effect of impeller pumping and fluid rheology on solids suspension in a stirred vessel." Can. J. Chem. Eng., Vol. 79 (2001), p. 177-186.

[5] Medek J., Fořt I.: "Pumping effect of impellers with flat inclined blades." Collect. Czech Chem. Commun., Vol. 44 (1979), p. 3077-3089.

[6] Fořt I., Medek J.: "Hydraulic and energetic efficiency of impellers with inclined blades." Proceedings of the $6^{\text {th }}$ European Conference on Mixing, Pavia (Italy), May 1988, p. 51-56. 
[7] Kresta S., Wood P.: "The flow field produced by a $45^{\circ}$ pitched blade turbine: Changes in the circulation pattern due to off bottom clearance." Can. J. Chem. Eng., Vol. 71 (1993), p. 42-53.

[8] Nienow A. W.: "On impeller circulation pattern due to off bottom clearance.” Chem. Eng. Sci., Vol. 22 (1997), No. 15, p. 2557-2565.

[9] Fořt I., Jirout T., Sperling R., Jambere S., Rieger F.: "Study of pumping capacity of pitched blade impellers." Acta Polytechnica, Vol. 42 (2002), No. 2, p. 68-72.

[10] Deeply dished bottoms for pressure vessels. Czech Standard ĆSN 425815, Prague 1980.

[11] Medek J.: "Power characteristics of agitators with flat inclined blades." Int. Chem. Eng., Vol. 20 (1980), No. 4, p. 664-772.

Ing. Jiří Brož

phone: + 420224352714

fax: +420224310292

e-mail: brozj@student.fsid.cvut.cz

Doc. Ing. Ivan Fořt, DrSc.

phone: +420224352713

e-mail: fort@fsid.cvut.cz

Prof. Ing. František Rieger, DrSc.

Department of Process Engineering

Czech Technical University in Prague

Faculty of Mechanical Engineering

Technická 4

16607 Praha 6, Czech Republic

Prof. Dr.-Ing. Reinhard Sperling

e-mail: reinhard.sperling@lbv.hs-anhalt.de

Ing. Solomon Jembere

Ing. Martin Heiser

Department of Chemical Engineering

Anhalt University of Applied Sciences

Hochschule Anhalt (FH)

Bernburger Str. 52-57

06366 Koethen, Germany 